\title{
Impacts of Climate Change on Monthly Electricity Consumption: A Case of Tianjin, China
}

\author{
Weidong Chen, Pengbang Wei*, Yufang Peng** \\ College of Management and Economics, Tianjin University, Tianjin, 300072, China
}

Received: 18 October 2020

Accepted: 25 January 2021

\begin{abstract}
The electricity supply chain, especially electricity demand, is very sensitive to climate. Developing a clear and quantitative understanding of the impacts of climate change on monthly electricity demand is critical for long-term generation capacity planning to maintain a reliable electricity supply system. A methodological framework applicable to city-level study is proposed and applied in Tianjin to investigate the impacts of climate change on monthly electricity consumption. By combining the empirical results with an ensemble of climate predictions under three Representative Concentration Pathways (RCPs), the study simulates the changes in monthly electricity demand caused by climate change in Tianjin by the end-of-century. The simulation results showed that climate change is projected to have severe impacts on the frequency and intensity of monthly peak electricity demand. Specifically, electricity demand in July would be $56 \%$ higher than that in November in 2099 under the RCP8.5 scenario. Climate change may drive substantial changes to the electricity supply chain, and our study is indicative of a need for adaptive strategies.
\end{abstract}

Keywords: climate change, monthly electricity consumption, climate simulations, adaptive strategies

\section{Introduction}

The electricity supply chain is very sensitive to climate variability [1]. Rising temperatures associated with global warming are likely to lead to an increase in electricity consumption during periods when air conditioning is required [2]. It has been suggested that the impacts of climate change on the electricity sector may account for the majority of economic damages by the end of the century $[3,4]$. The temperature variability caused by climate variability may cause the short-term

*e-mail: weipb666@163.com

**e-mail: pengyufang_222@163.com fluctuation of regional electricity consumption, and the temperature rise caused by climate change may also increase the social electricity demand in the long term [5-9]. The global greenhouse gas emission level has been rising in the past 150 years and has reached a level not seen in at least 400 thousand years [10]. By 2012 , the earth's surface temperature level had risen by $0.85^{\circ} \mathrm{C}$ compared with that before industrialization [11]. At the same time, due to the lag of the response of the earth's climate system to greenhouse gas, the global temperature may continue to rise by at least another $0.5^{\circ} \mathrm{C}$ even if the current level of greenhouse gas in the atmosphere is no longer rising $[12,13]$. As greenhouse gas emissions continue to rise $[14,15]$, the future climate change may further drive a substantial impact on electricity demand [16]. 
In current economies over the world, electricity is the most indispensable form of energy in households and firms [17]. How to understand the impacts of climate variability on electricity consumption is an ambitious question that needs to be answered. More efforts may also be needed to study the significance of future changes in electricity supply chain caused by climate change. It is certainly no surprise that numerous studies have emerged to address how climate variability affects the electricity sector. Almost all scholars suggest that the electricity sector is sensitive to climate variability, especially in regional electricity demand [1821]. Generally, climate variability may affect electricity consumption in many ways $[22,23]$.

In order to further explore the relationship between climate change and electricity consumption, how to select appropriate climate factors and how to measure the degree of climate change should be figured out first. Climate variability is mainly manifested in temperature rise, and the energy-temperature relationship is usually hypothesized as a U-shaped curve in most literature. According to Gupta [24], the U-shaped curve of powertemperature response function can be displayed in Fig. 1, where the minimum point is the threshold, determined by the balance temperature for requirement cooling and requirement heating. In most empirical studies, the temperature variable is generally measured by the conception of heating degree days (HDD) and cooling degree days (CDD). HDD is used to quantify the heating demand degree defined as the aggregate degrees below the threshold over a period, and CDD is used to quantify the demand for refrigeration degree defined as the aggregate degrees above the threshold over a period. Kaufmann et al. [25] considered $65^{\circ} \mathrm{F}$ $\left(18.3^{\circ} \mathrm{C}\right)$ as the threshold in their research, while the actual threshold should be specific to the local characteristics such as living habits of residents and building insulation. Therefore, the threshold should be determined according to specific local conditions when to investigate the impact of climate variability on electricity consumption in a specific region.

How climate change affects electricity consumption in specific regions has also caused many researchers' attention. Zachariadis and Hadjinicolaou [26] assessed additional electricity demands and the associated costs caused by climate variability in the Mediterranean island of Cyprus through an interdisciplinary approach that combines economics with climate science. Hollanda et al. [27] incorporated climate uncertainty into a long-term electricity demand forecasting method and projected the electricity demand in Brazil under different climate scenarios. And their results indicated that the annual average electricity consumption in Brazil would continue to increase until peaking in 2060. Fan et al. [28] estimated the impacts of climatic factors on electricity consumption in China by using panel data of 30 provinces from 1995-2016, and the empirical results showed the potential effects of climate variability on China's annual electricity consumption. Burillo et al. [29] analyzed the impacts of climate variability on the electricity consumption of Los Angeles, and they pointed out that annual electricity demand was projected to increase by $4-8 \%$ in 2060 due to rising air temperatures from climate change.

According to the above literature review, developing a comprehensive understanding of the impacts of climate change on the electricity supply chain is critical for building a reliable electricity supply system. Therefore, it is worthy to study this significant and complex issue from multiple perspectives. The paper aims to investigate the impacts of climate change on a specific region's monthly electricity consumption. The possible and contributions of this study are as follows. This paper proposes a feasible methodological framework to evaluate the impact of climate change on regional electricity demand, which can reasonably

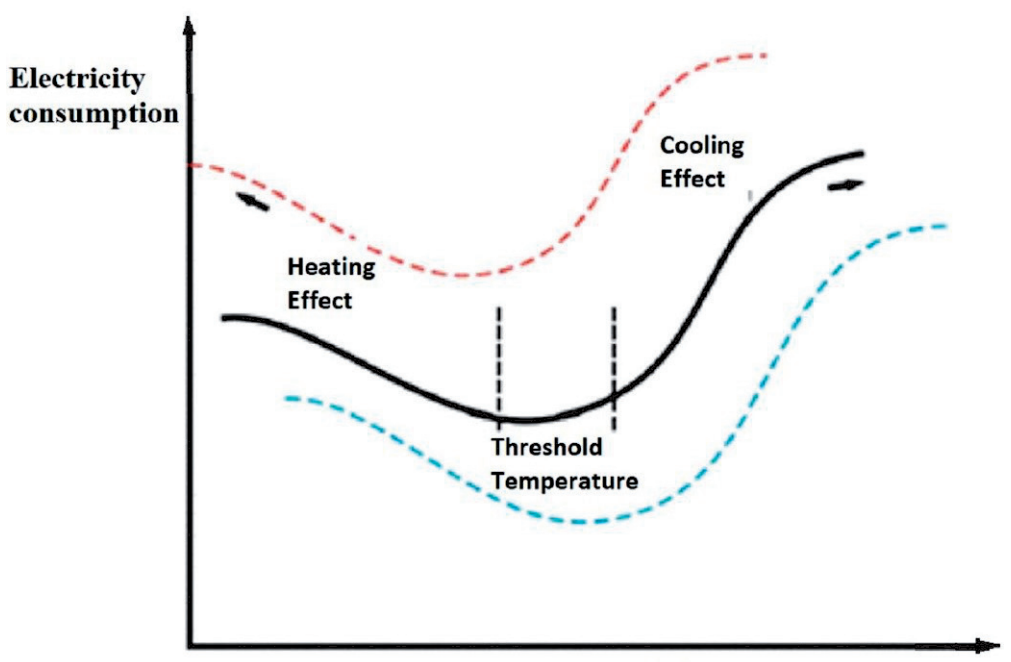

Temperature

Fig. 1. The relationship between electricity consumption and temperature. 
eliminate the influence of other factors, such as GDP, technological progress, et al. The method proposed in this paper is on the monthly scale, which can both assess the short-time impact of seasonal cycle temperature change on electricity consumption and the longterm impact of climate change on electricity demand comprehensively. By taking Tianjin as the study area of the empirical analysis, this paper may provide valuable experience for other urban electricity departments in North China to cope with climate change. The paper may enable a better understanding of the severe impacts on the frequency and intensity of monthly peak electricity demand caused by climate change, which is valuable to maintaining reliable electricity systems.

The remainder of this paper is organized as follows: Section 2 elaborates on Material and Methods. Section 3 presents the Results and Discussion, followed by some conclusions of the paper in Section 4.

\section{Material and Methods}

\section{Explanatory Variables}

Following other studies [30-32], the variables used in this research are carefully selected with regard to data availability and economic theory. Considering the aim of our research, this study divides the influencing factors into climatic factors and non-climatic factors.

\section{Climatic Variables Selection and Processing}

Figuring out how to select appropriate climate factors and how to measure the degree of climate variability. Then we can further consider how to construct climate indicators to establish the relationship between climate change and electricity demand. At present, the linear climate-power load response model usually assumes that there is a transient variability from heating required environment to the cooling required environment for infinitesimal deviation from the balance point temperature. This is an ideal assumption. In reality, there is a temperature range, and during this interval, the electricity consumption may not respond to the temperature change [33]. Therefore, there are studies trying to improve the linear V-shaped model by introducing the temperature comfort zone gradually, which can keep the indoor temperature at the desired level without heating or cooling load [34].

Then how to obtain a reasonable comfort zone threshold becomes very important. Wu et al. (2015) [35] used nationwide temperature comfort data supplied by the Ministry of Housing and Urban-Rural Development of China, and they found when air temperature ranges from $11^{\circ} \mathrm{C}$ and $17^{\circ} \mathrm{C}$, approximately $40 \%$ of residents feel comfortable, and $10 \%$ of residents feel uncomfortable. On the basis of previous studies, we first find out the lowest electricity consumption month in the region before summer in the past 15 years. Then, we take the average daily temperature of the first tenday period of the month as the balance point for space heating, and take the average daily temperature of the last ten-day period of this month as the balance point for space cooling. The linear model schematic of the power-temperature response function considering the temperature comfort zone is shown in Fig. 2.

As shown in Fig. 2, the right minimum point is the threshold value of the balance point for space cooling, and the left minimum point is the threshold value of the balance point for space heating. Social and economic factors such as GDP and living habits of local residents may affect the horizontal position and slope of the power-temperature response function [31, 36, 37]. According to the widely used variables in many studies, we also use heating degree days (HDD) and cooling degree days (CDD) as proxy variables of temperature to measure the nonlinear relationship between power demand and temperature. Following Ahmed et al. (2018) [38], the HDD and CDD can be defined by Eq. (1) and Eq. (2).

$$
H D D=\sum_{i=1}^{d}\left(T_{b h}-T_{i}\right), \quad \text { if }\left(T_{b h}>T_{i}\right)
$$

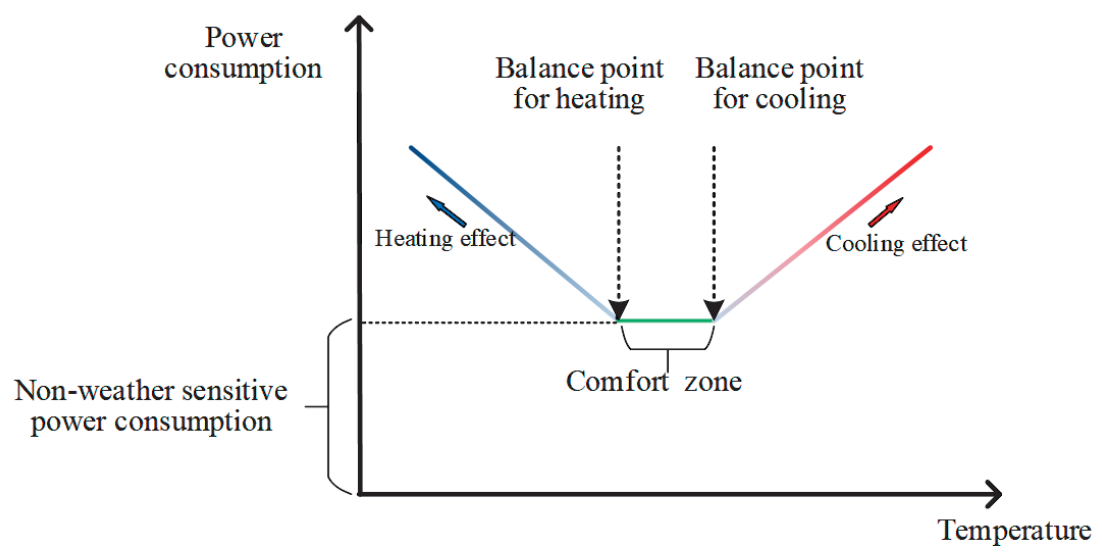

Fig. 2. Linear model schematic of the relationship between temperature and electricity consumption. 


$$
C D D=\sum_{i=1}^{d}\left(T_{i}-T_{b c}\right), \quad \text { if }\left(T_{b c}<T_{i}\right)
$$

...where $d$ is the number of days in the research scale, $T_{b n}$ represents the balance point for space heating, $T_{i}$ represents the daily average temperature on day $i$, and $T_{b c}$ represents the balance point for space cooling.

\section{Non-Climatic Variables Selection and Processing}

Electricity is an indispensable input for national production and daily life. Many studies have proved that economic growth and the rising national income may increase the demand for electricity [39, 40]. In addition to these factors, there are many other social factors that affect the electricity demand of an area. Among the above-mentioned non-climatic factors, some factors such as economic growth and national income that have a positive impact on electricity consumption, and some factors including technological progress have a negative impact on electricity consumption [41]. And there are some other factors such as living habits of residents that are hard to identify whether it is a positive or negative impact on region electricity demand. However, it is too difficult to gain a quantitative measure for those nonclimatic factors because of their complexity. Although these variables are difficult to quantify effectively, they also change very little in a short period of time [42-44]. Considering the importance and data accessibility, we select economic development as the non-climatic factor in this study, and the district level GDP is taken as the proxy variable of economic development.

\section{Methodological Framework and Model Specification}

In order to eliminate the influence of these hardly quantified non-climatic factors on the evaluation results, this paper conducts the research on the monthly scale to use the characteristic that these variables are almost unchanged in a short time. Specifically, we incorporate climatic factors into the electricity demand model by establishing an econometric model to evaluate the impacts of climate variability on monthly electricity consumption using panel data of 12 months in many years. Elaborated by this approach, this research can explore the impacts of long-term climate change on electricity demand in a specific region from a microscale perspective.

The modeling steps used to investigate the impacts of climate change on monthly electricity consumption in a specific region are as follows.

1. Testing the trends of study region's temperature with the help of Mann-Kendall trend test method.

2. Computing the local HDD and CDD data based on the daily average temperature data of the region.

3. Elaborating the panel data regression model based on the data availability and econometric theory.
4. Assessing the long-term impacts of climate change on monthly electricity demand based on the constructed model with the help of monthly panel data. In this step, the fixed-effects model, randomeffects model, and mixed model are all constructed for panel data model estimation, while an F-test and a Hausman test would be undertaken to explore which model is the most appropriate model in the specific case.

5. Combining results from the empirical model and future predictions of climate change to simulate future changes in monthly electricity demand under different climate change scenarios.

\section{Mann-Kendall Trend Test}

Aiming to explore the impact of climate change on regional electricity consumption in the paper, we should grasp the changing trend of the local climate firstly. There are two classes of approaches to detect the trend in time series variables: parametric methods and nonparametric methods. Parametric methods are suitable for independent and normally distributed data, while the nonparametric methods can be used in the data that is only independent.

Because the variables used in this study are not normally distributed data, the nonparametric method should be used in the paper. Mann-Kendall test method is a classical nonparametric statistical method proposed by Mann [45] and Kendall [46]. Its advantage is that the detected data do not need to follow a certain distribution and cannot be easily interfered by a few abnormal values. Mann-Kendall trend test can effectively identify whether a natural phenomenon is being in natural fluctuation or varying in a significant trend, which has been recommended by the World Meteorological Organization and widely used in the analysis of climate variability trends such as temperature [47]. In view of the above, we use Mann-Kendall trend test to detect the trend of climatic variables.

The Mann-Kendall test statistic S is calculated as

$$
S=\sum_{k=1}^{n-1} \sum_{j=k+1}^{n} \operatorname{sgn}\left(x_{j}-x_{k}\right)
$$

...where $\mathrm{n}$ is the number of data points in time series $\mathrm{X}, x_{k}$ and $x_{j}$ are time series values at the $k$ th and $j$ th time instances in the time series $\mathrm{X}$ respectively, and $\operatorname{sgn}\left(x_{j}-x_{k}\right)$ is the sign function as:

$$
\operatorname{sgn}\left(x_{j}-x_{k}\right)=\left\{\begin{array}{l}
+1, \text { if } x_{j}-x_{k}>0 \\
0, \text { if } x_{j}-x_{k}=0 \\
-1, \text { if } x_{j}-x_{k}<0
\end{array}\right.
$$

The statistical parameter for the Mann-Kendall trend test is the value $\mathrm{Z}$, and $\mathrm{Z}$ is given as: 


$$
Z_{S}=\left\{\begin{array}{c}
\frac{s-1}{\sqrt{\operatorname{Var}(S)}}, \text { if } S>0 \\
0, \text { if } S=0 \\
\frac{s+1}{\sqrt{\operatorname{Var}(S)}}, \text { if } S<0
\end{array}\right.
$$

...where $\operatorname{Var}(S)$ is variance of statistic $S$. And when the number of data points in time series $\mathrm{X}$ is big (usually bigger than 10 [47]), the $\operatorname{Var}(S)$ can by computed as:

$$
\operatorname{Var}(S)=\frac{n(n-1)(2 n+5)-\sum_{i=1}^{m} t_{i}\left(t_{i}-1\right)\left(2 t_{i}+5\right)}{18}
$$

...where $\mathrm{n}$ is the number of data points in time series $\mathrm{X}$, $\mathrm{m}$ is the number of tied groups in time series $\mathrm{X}, t_{i}$ is the number of ties of extent $i$, and a tied group is a set of data having the same value.

Based on the Mann-Kendall method, a positive value of $Z_{s}$ means an increasing trend while the negative $Z$ value indicates a decreasing trend. The changing trend is considered significant at the specific $\alpha$ significance level when $\left|Z_{s}\right|>\left|Z_{1-\alpha / 2}\right|$, and the needed $\left|Z_{1-\alpha / 2}\right|$ can be obtained from the standard normal distribution table. Significance levels $\alpha=0.01$ and $\alpha=0.05$ would be used in this study. And if $\left|Z_{s}\right|>2.576$ or $\left|Z_{s}\right|>1.96$, the null hypothesis of no trend is rejected at the $1 \%$ or $5 \%$ significance level respectively.

\section{Electricity Consumption Regression Model}

The monthly level panel data from many years are used in this study to reflect the essential relationship between electricity consumption and climate variability. There are two main reasons for using the monthly panel data. One is to eliminate the influence of other hardly quantitative measuring non-climatic factors because they change very little at a monthly level [48]. And the other reason is that monthly panel data can be used to comprehensively assess the short-time impact of seasonal cycle temperature variability on electricity consumption and the long-term impact of climate change on electricity consumption because daily temperatures not only vary with seasonal changes in a year but also vary with long-term climate change.

In addition, in order to eliminate the influence of different days of each month, the monthly data used in the model are divided by the number of days included in the current month. Specifically, the data of January, March, May, July, August, October and December are divided by 31, and the data of April, June, September and November are divided by 30 , and the data of leap year February are divided by 29 and other February are divided by 28. Before panel regression, in order to avoid pseudo regression and ensure the validity of the estimation results, the Levin-Lin-Chu (LLC) unit root test [49] and ADF - Fisher unit root test [50] would be conducted on all the variables. In order to guarantee the reliability of the study, the fixed-effects model (FEM), random-effects model (REM), and mixed model (MM) are all constructed for panel data model estimation. And then an F-test and a Hausman test [51, 52] were undertaken to explore which model is the most appropriate method in this case. The panel data model is defined in Eq. (7).

$$
\begin{gathered}
E C_{i t}=c+\alpha_{i}+\gamma_{t}+\beta_{1} \cdot G D P_{i t}+\beta_{2} \cdot H D D_{i t} \\
+\beta_{3} \cdot C D D_{i t}+\varepsilon_{i t}
\end{gathered}
$$

...where $E C_{i t}$ represents the regional electricity consumption for month $i$ of year $t$. $c$ represents the intercept term. $\alpha_{i}$ represents the specific cross-section effect, which represents the influence of different individuals in the same cross-section on the value of the intercept term in the panel data regression model. $\gamma_{t}$ represents the temporal point fixed effect, reflecting the temporal difference of electricity consumption in the model. $\beta_{1}, \beta_{2}$, and $\beta_{3}$ are regression coefficients. $\varepsilon_{i t}$ is the random error term of the model. GDP $P_{i t}$ represents the monthly gross domestic product of the study region. $H D D_{i t}$ and $C D D_{i t}$ are the climatic variables as mentioned in the above paper.

\section{Simulations on the Impacts of Future Climate Change}

In order to explore the impacts of future climate change on electricity demand, we combine the results of the econometric model with the predicted climate changes. The paper uses simulations of the IPCC's Representative Carbon Pathway (RCPs) scenarios [53, 54], i.e. RCP2.6, RCP4.5 and RCP8.5, to define a range of possible future temperature anomalies and add those anomalies to the historical temperature range from local weather stations. This approach could give us a set of projected time series of climate variables for the study region. We then use the coefficients derived from the estimated model to predict future monthly electricity demand under different climate change scenarios. In order to investigate percentage changes, we also compare the estimated results with a baseline scenario in which no warming happens.

\section{Results and Discussion}

\section{Study Area and Data Collection}

\section{Tianjin City}

The authors of the paper chose Tianjin as the study area of the empirical analysis. We use city boundary lines for Tianjin to define local areas for electricity consumption and air temperature because the geopolitical boundaries reasonably frame the existing electricity infrastructure, and the public data are generally accessible in that format. Tianjin is one of the four municipalities in China, which is located in the 


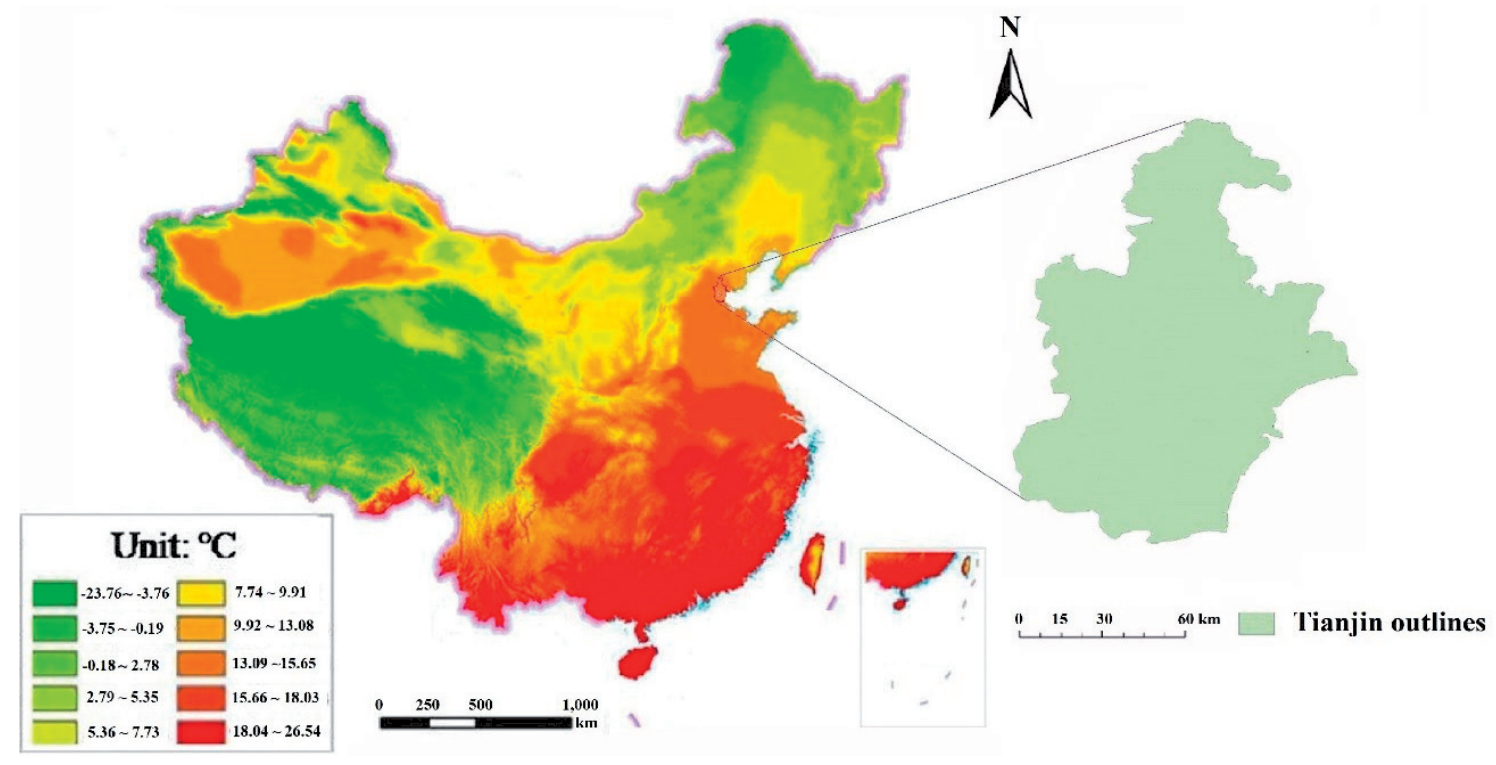

Fig. 3. The geographical location and climate situation of Tianjin (temperature is year average in 2010). Sources: National Meteorological Information Center of China.

northeast part of North China Plain $\left(38^{\circ} 34^{\prime}-40^{\circ} 15^{\prime} \mathrm{N}\right.$, $\left.116^{\circ} 43^{\prime}-118^{\circ} 04^{\prime} \mathrm{E}\right)$ [55]. The geographical location and temperature situation of Tianjin are shown in Fig. 3. Tianjin has a large-scale electricity infrastructure, and its climate could be representative of the surrounding areas.

In recent years, the electricity load of Tianjin keeps on breaking the new record in hot weather usually in July every year [56]. It is very important to assess the impacts of climate change on Tianjin's electricity demand for dealing with the temporary electricity shortage caused by climate change. Therefore, in this paper, Tianjin is chosen as an interesting case to provide experience for other urban electricity departments in North China to cope with climate change.

\section{Variable Description and Data Sources}

As elaborated in Section 3, the monthly electricity consumption, GDP, HDD, and CDD data are needed in this study. Among them, the monthly electricity consumption data for the period 2000-2018 were collected from the Tianjin municipal government information disclosure column website, which was issued monthly by the Tianjin Municipal Bureau of Statistics. Because monthly regional level Gross Domestic Production data in Tianjin have not been released ever, we take the corresponding quarterly GDP data divided by 3 as the monthly GDP. In order to get the monthly HDD and CDD data for the period 2000-2018, we collected the daily average temperature data of Tianjin from the National Meteorological Information Center of China. The reason why we chose the daily average temperature here is that the daily average temperature is the average value of hourly observations in a day, which could better represent the temperature of a day than the daily max temperature. The descriptive analysis of each variable used in this study has been summarized in Table 1 .

\section{Empirical Results and Discussion \\ Changing Trends in the Temperature of Tianjin}

Because climate variability is mainly manifested in temperature rise and the temperature is the main climatic factor affecting electricity consumption,

Table 1. Descriptive statistics of variables used in the study.

\begin{tabular}{|c|c|c|c|c|c|c|c|c|}
\hline Variables & Description & Unit & N & Mean & Median & Max & Min & S.D \\
\hline EC & Monthly electricity consumption & 100 million kWh & 228 & 45.96 & 46.56 & 85.76 & 13.35 & 19.74 \\
\hline GDP & Monthly regional GDP & billion RMB Yuan & 228 & 76.07 & 59.67 & 171.53 & 11.82 & 52.24 \\
\hline HDD & Monthly heating degree days & ${ }^{\circ} \mathrm{C}^{*}$ day & 228 & 103.32 & 4.15 & 511.60 & 0.00 & 142.08 \\
\hline CDD & Monthly cooling degree days & ${ }^{\circ} \mathrm{C}^{*}$ day & 228 & 110.43 & 28.85 & 392.80 & 0.00 & 131.98 \\
\hline
\end{tabular}

Note: $\mathrm{N}$ and S.D are the numbers of observation and standard deviations of the variables respectively. 
Table 2. Mann-Kendall trend test results of the daily average temperature for overall scale and monthly scale over the period 2000 to 2018 .

\begin{tabular}{|c|c|}
\hline Variable series & $Z_{s}$ \\
\hline Overall scale & $2.8225^{* * *}$ \\
\hline January & $4.8636^{* * *}$ \\
\hline February & $2.5809^{* * *}$ \\
\hline March & $1.9643^{* *}$ \\
\hline April & $1.9608^{* *}$ \\
\hline May & $2.5958^{* * *}$ \\
\hline June & $2.2591^{* *}$ \\
\hline July & $2.0166^{* *}$ \\
\hline August & $4.7121^{* * *}$ \\
\hline September & $3.8916^{* * *}$ \\
\hline October & $2.9160^{* * *}$ \\
\hline November & $2.7672^{* * *}$ \\
\hline December & $3.5557^{* * *}$ \\
\hline
\end{tabular}

Note: $Z_{s}$ is the Mann-Kendall trend test statistical parameter.

${ }^{* *}$ Denote that there is a statistically significant trend at the $5 \%$ significance level. ${ }^{* * *}$ Denote that there is a statistically significant trend at the $1 \%$ significance level.

we should make clear the changing trend of the local temperature first. The Mann-Kendall trend test method has been applied to the time series of daily average temperature in Tianjin. In this study, we tested the daily average temperature change trend on the overall scale and the monthly scale in the study period. The overall scale is to test the time series of all daily temperature data during the study period. And the monthly scale is to test the time series composed of daily temperature data of the same month in every year (For example, the changing trend of daily temperature in January is to test the time series composed of daily temperature data in all Januaries in the period 2000 to 2018).
The results of trend tests for the daily average temperature of overall scale and monthly scale in Tianjin over the period 2000-2018 are presented in Table 2. There are significant increasing trends in Tianjin's daily average temperature for the overall scale and 12 monthly scales at $1 \%$ or $5 \%$ significance levels. On the overall scale, Tianjin's daily average temperature existed a significant increasing trend at $1 \%$ significance level from 2000 to 2018. Moreover, on the monthly scale, each month showed a significant increasing trend at $1 \%$ or $5 \%$ significance levels during the study period. The comprehensive results indicate that the daily temperature in Tianjin has a significant rising trend, and we should pay attention to the impacts of this climate variability on the regional electricity demand.

\section{Changes in HDD and CDD of Tianjin}

Based on the daily average temperature data, we computed the monthly HDD and CDD in Tianjin from 2000 to 2018. For visual display, we list seven equal time span representative HDD and CDD, where Fig. 4 and Fig. 5 reflect the change trends of the monthly HDD and CDD data respectively.

As shown in Fig. 4, the monthly HDD data of Tianjin shows a U-shaped curve, existing a downward trend from January to April, an upward trend from October to December, and almost zero from May to September. During the investigated 19 years, the U-shape curve of HDD is becoming flatter, which also intuitively shows that although there are fluctuations, it does exist a downward trend of monthly HDD in Tianjin from 2000 to 2018. It can also be seen that the downward trend is more obvious in January and December (specifically, the monthly HDD in January has dropped from $511.68^{\circ} \mathrm{C} *$ day in 2000 to $306.8^{\circ} \mathrm{C} *$ day in 2018 ).

The monthly CDD data of Tianjin shows an inverted U-shaped curve with an upward trend from April to July, a downward trend from August to October, and almost zero from January to March and November to December every year. From 2000 to 2018, the U-shape

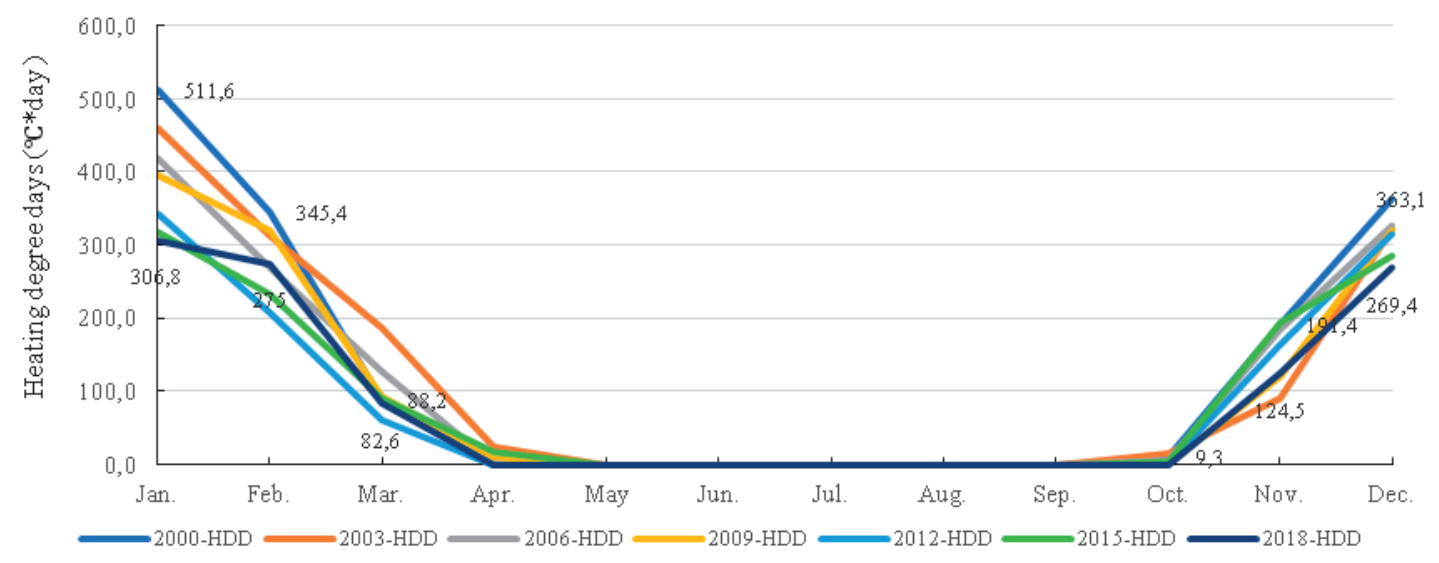

Fig. 4. The monthly HDD in Tianjin from 2000 to 2018. 


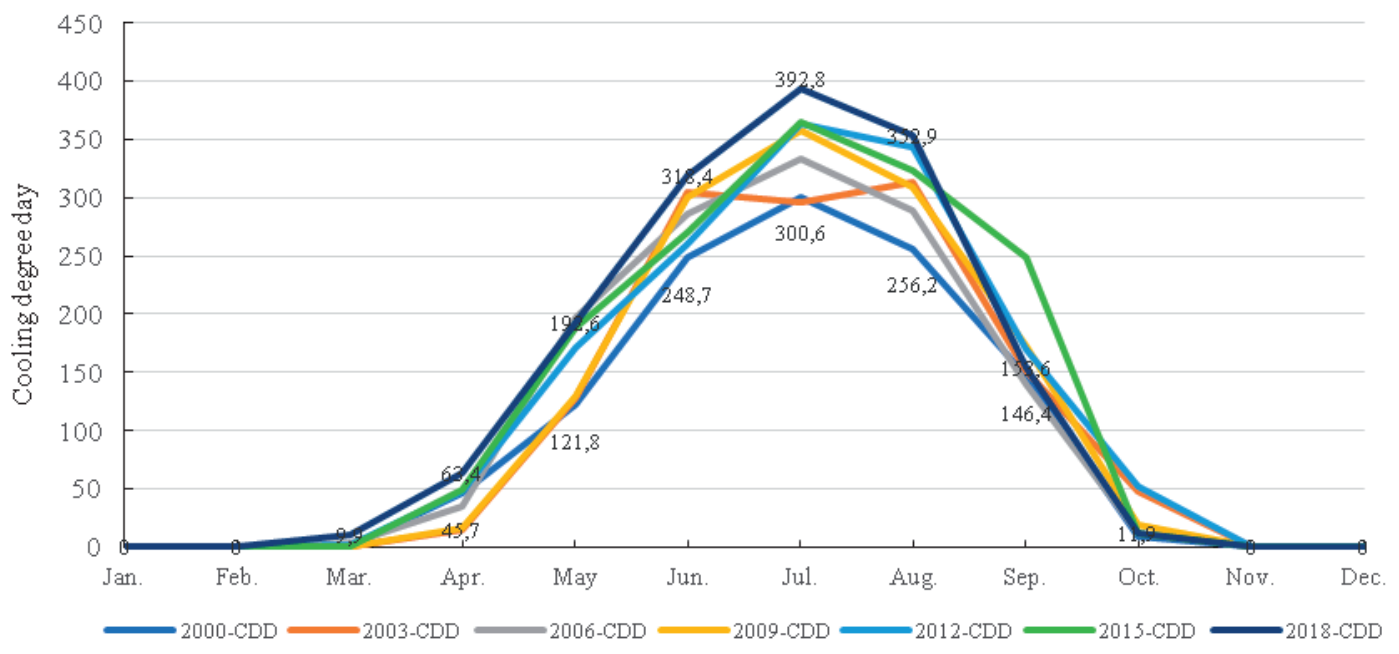

Fig. 5. The monthly CDD in Tianjin from 2000 to 2018.

Table 3. The stationary test results.

\begin{tabular}{|c|c|c|c|c|c|}
\hline \multirow{2}{*}{ Details } & \multicolumn{2}{|c|}{ Levin-Lin-Chu unit root test } & \multicolumn{2}{|c|}{ ADF - Fisher unit root test } & \multirow{2}{*}{ Remarks } \\
\cline { 2 - 5 } & Statistic & Probability & Statistic & Probability & $\mathrm{I}(0)$ \\
\hline EC & $-2.86401^{* * *}$ & 0.0021 & $26.4574^{* *}$ & 0.0239 & $\mathrm{I}(0)$ \\
\hline GDP & $-9.40362^{* * *}$ & 0.0000 & $45.5071^{* * *}$ & 0.0051 & $\mathrm{I}(0)$ \\
\hline HDD & $-6.20569^{* * *}$ & 0.0000 & $48.5915^{* * *}$ & 0.0000 & $\mathrm{I}(0)$ \\
\hline CDD & $-3.04867^{* * *}$ & 0.0011 & $45.6846^{* * *}$ & 0.0001 & \\
\hline
\end{tabular}

** Denote that there is a statistical significance at the $5 \%$ level. *** Denote that there is a statistical significance at the $1 \%$ level.

curve of HDD is becoming higher and fatter, which also indicates intuitively that although there are fluctuations, it does exist a significant upward trend of monthly CDD in Tianjin. It can also be seen that the upward trend in July and August is particularly obvious (specifically, the monthly $\mathrm{CDD}$ in July has increased from $300.6^{\circ} \mathrm{C} *$ day in 2000 to $392.8^{\circ} \mathrm{C} *$ day in 2018 ).

\section{Panel Data Model Estimation}

Before panel data regression, in order to avoid spurious regression and ensure the validity of the estimation results, the Levin-Lin-Chu (LLC) unit root test [49] and ADF - Fisher unit root test [50] were conducted on the panel data to test for whether all the individuals time series are being stationary or not. The stationary test results are shown in Table 3. The results of both LLC test and ADF - Fisher test showed that all variables used in the analysis are stationary at levels, and there is no need to conduct panel co-integration tests.

Thereafter, a panel data regression analysis of Tianjin over the period 2000 to 2018, is undertaken for monthly electricity consumption against GDP, HDD, and CDD. In this study, the fixed-effects model, randomeffects model and mixed model are all constructed for panel data model estimation. And then an F-test and a Hausman test are undertaken to explore which model is the most appropriate method in this case. The summary of panel data regression results is shown in Table 4. Specifically, when making a choice among the mixed model and fixed-effects model, the null hypothesis is rejected at the $1 \%$ significance level based on the F-test results, so the fixed-effects model should be more suitable. Similarly, when making a choice between the fixed-effects model and the randomeffects model, the null hypothesis is rejected at the $1 \%$ significance level based on the results of Hausman test, which indicates that the basic hypothesis of the random-effects model is not satisfied. Therefore, in this empirical study, it should better to use the fixedeffects model to estimate the coefficient of the panel data regression equation. Additionally, a comparison of the three models' results indicates that the estimated coefficients of the three models are close to each other, which also indicates the reliability of the regression results.

The results in Table 4 show that GDP has a significant impact on electricity consumption in Tianjin. Specifically, one unit increase in GDP would result in about 0.32 unit increase in monthly electricity consumption (at the $1 \%$ significance level), which indicates that economic development would increase the energy demand significantly. A comparison of the 
Table 4. Summary of panel data regression results.

\begin{tabular}{|c|c|c|c|}
\hline Variables/ coefficients & FEM & REM & MM \\
\hline \multirow{2}{*}{$G D P\left(\beta_{1}\right)$} & $0.320450^{* * *}$ & $0.360048^{* * *}$ & $0.360212^{* * *}$ \\
\hline & $(0.012204)$ & $(0.007033)$ & $(0.008020)$ \\
\hline \multirow{2}{*}{$H D D\left(\beta_{2}\right)$} & $0.064964^{* * *}$ & $0.005425^{*}$ & $0.015738^{* * *}$ \\
\hline & $(0.018432)$ & $(0.007409)$ & $(0.003710)$ \\
\hline \multirow{2}{*}{$C D D\left(\beta_{3}\right)$} & $0.094146^{* *}$ & $0.018094^{* *}$ & $0.023257^{* * *}$ \\
\hline & $(0.029823)$ & $(0.008279)$ & $(0.003990)$ \\
\hline \multirow{2}{*}{ Constant } & $17.41151^{* * *}$ & $15.78034^{* * *}$ & $14.01929^{* * *}$ \\
\hline & $(2.737129)$ & $(1.841507)$ & $(1.059469)$ \\
\hline Cross-section fixed effect & Yes & None & None \\
\hline Period fixed effect & None & None & None \\
\hline Cross-section random effect & None & Yes & None \\
\hline Period random effect & None & None & None \\
\hline Observations & 228 & 228 & 228 \\
\hline R-squared & 0.968383 & 0.956706 & 0.959923 \\
\hline Adjusted R-squared & 0.963676 & 0.955590 & 0.958582 \\
\hline \multirow{2}{*}{ F-test } & $7.695094^{* * *}$ & & \\
\hline & {$[0.0000]$} & & \\
\hline \multirow{2}{*}{ Hausman test } & & $17.447359^{* * *}$ & \\
\hline & & {$[0.0006]$} & \\
\hline
\end{tabular}

Note: FEM represents the fixed-effects model; REM represents the random-effects model; MM represents the mixed model.

The standard error of each coefficient is in brackets. The probability values of F-test and Hausman test are in the corresponding square brackets respectively. * Denote that there is a statistical significance at the $10 \%$ level. ** Denote that there is a statistical significance at the $5 \%$ level. $* * *$ Denote that there is a statistical significance at the $1 \%$ level.

coefficients of GDP and climatic variables (HDD and CDD) shows that the elasticity coefficient of GDP is much higher than those climatic factors, which indicates that impact of the economic growth on the electricity demand was greater than the impact of climate variability. This result is consistent with the studies by Ruth and Lin (2006) [57], and Fan et al. (2019) [28], who also demonstrated that the macroeconomic variables have a greater impact on electricity consumption than climatic variables.

The regression results could suggest, accordingly, that HDD and CDD significantly influence Tianjin's electricity consumption. Specifically, both HDD and CDD play a positive role in electricity demand. If HDD increase one unit, the monthly electricity consumption would expect to increase 0.065 unit (at the $1 \%$ significance level). And if CDD increase one unit, the monthly electricity consumption would expect to increase 0.094 unit (at the $1 \%$ significance level). Interestingly, the elasticity coefficient of CDD is higher than HDD, which indicates that the cooling demand behaviors may have a greater influence on electricity consumption than heating demand behaviors.
In other words, a hot temperature could have a greater marginal influence on electricity consumption than a cold temperature. This may be mainly attributed to the current heating and cooling mode in Tianjin, where the heating system is mainly derived from coal and natural gas, and electrical equipment is only used as auxiliary heating equipment [58], but the refrigeration system is mainly equipped by electrical equipment such as air conditioners.

\section{Impacts of Climate Change on Monthly Electricity Consumption}

This part shows the results revealing the impacts of climate change on monthly electricity demand in Tianjin. We estimate the climatic variables response function for monthly electricity demand according to the panel data regression results listed in Table 4 . When the non-climatic variable is controlled, Fig. 6 illustrates the response function of monthly electricity consumption to HDD and CDD, which is relative to the omitted benchmark month (April), a month with the least HDD and CDD. The stacked area chart of 


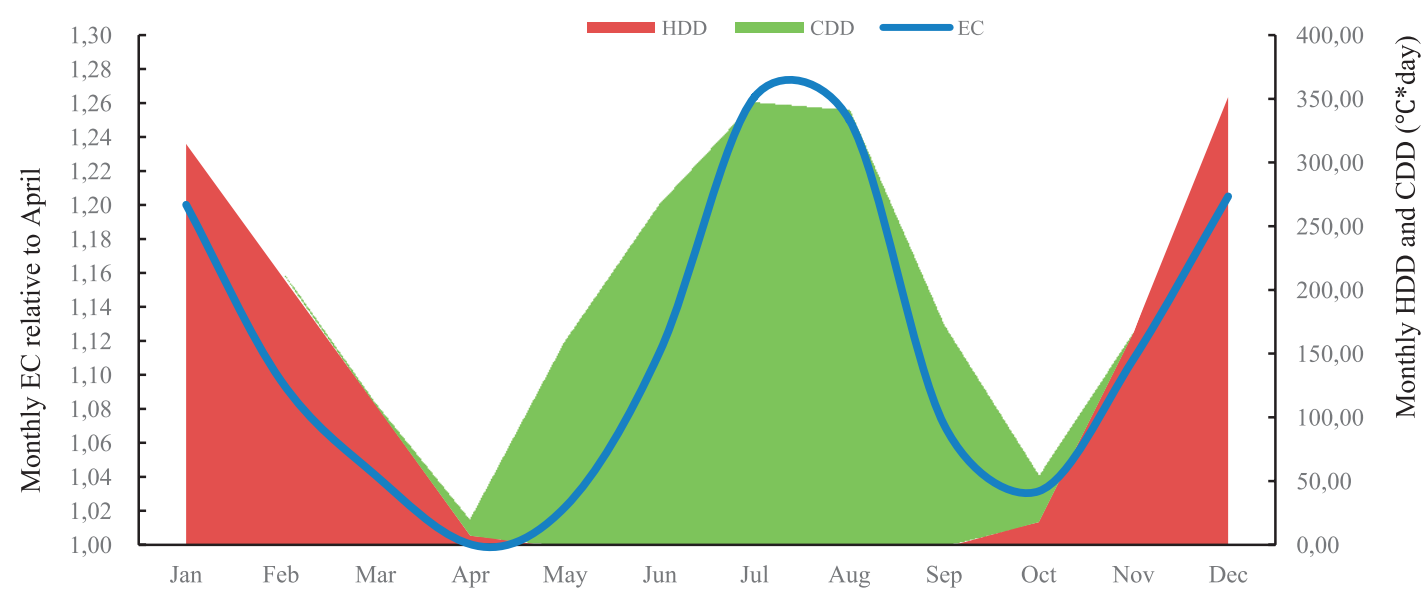

Fig. 6. Response function of monthly electricity consumption to HDD and CDD. Note: EC represents electricity consumption, which is corresponding to the left primary axis, while the CDD and HDD data correspond to the right secondary axis.

the HDD and CDD distribution is also plotted on the same figure to illustrate the support of the data used to identify the curve statistically.

As shown in Fig. 6, the height of the blue line at each month represents the differences in monthly electricity consumption relative to April, which has the least sum of HDD and CDD. HDD in January is the highest, and electricity consumption in January is $20.5 \%$ higher than that in April. While CDD is the highest in July, and electricity consumption in July is $26 \%$ higher than that in April. Controlling non-climatic factors, electricity consumption is predominantly driven by the extent to which an area need heats or cools with electricity. Tianjin has a nearly symmetric response function for electricity consumption across HDD and CDD. While compared with HDD, CDD has a higher load response resulting from cooling demand. This difference is consistent with the different elasticity coefficients of HDD and CDD.

It is also worth to note that the EC curve is always in the red HDD area but it can exceed the green CDD area in July and August with the most cooling demand. The difference in the relative shape of EC curve has particular implications for climate change. At the same time, in Tianjin, from 2000 to 2018, the annual growth rates of monthly electricity consumption in January and July are $8.3 \%$ and $9.6 \%$ respectively. The growth rate of electricity consumption in the hottest month (July) is

Table 5. Simulated results of future temperature projections' impacts on HDD, CDD, and electricity consumption in Tianjin under the three climate scenarios.

\begin{tabular}{|c|c|c|c|}
\hline \multirow{4}{*}{ Scenarios } & Variables & 2050 & 2099 \\
\hline \multirow{4}{*}{ RCP2.6 } & Temperature & $+0.5^{\circ} \mathrm{C}$ & $+1.3^{\circ} \mathrm{C}$ \\
\cline { 2 - 4 } & HDD & $-6.0 \%$ & $-14.9 \%$ \\
\cline { 2 - 4 } & CDD & $+5.6 \%$ & $+14.3 \%$ \\
\cline { 2 - 4 } & EC & +372 million $\mathrm{kWh}(0.4 \%)$ & +1017 million $\mathrm{kWh}(1.2 \%)$ \\
\cline { 2 - 4 } & Temperature & $+0.9^{\circ} \mathrm{C}$ & $+2.3^{\circ} \mathrm{C}$ \\
\cline { 2 - 4 } & HDD & $-11.4 \%$ & $-28.0 \%$ \\
\cline { 2 - 4 } & CDD & $+10.9 \%$ & $+27.8 \%$ \\
\hline \multirow{5}{*}{ RCP8.5 } & EC & +762 million $\mathrm{kWh}(0.9 \%)$ & +2210 million $\mathrm{kWh}(2.6 \%)$ \\
\cline { 2 - 4 } & Temperature & $+2.0^{\circ} \mathrm{C}$ & $+5.2^{\circ} \mathrm{C}$ \\
\cline { 2 - 4 } & HDD & $-25.4 \%$ & $-59.9 \%$ \\
\cline { 2 - 4 } & CDD & +1939 million $\mathrm{kWh}(2.2 \%)$ & $+66.2^{\circ} \%$ \\
\hline
\end{tabular}

Note: The timescale on which results are based is a year, and the numbers in brackets are projected percentage change of corresponding variables compared to the benchmark year. Changes in temperature are sourced from [54,60,61], and changes in all the variables are based on the 2018 benchmark. 
higher than that in the coldest month (January). Hence it can be reasonably predicted that climate change may further aggravate the peak electricity demand in July.

\section{Simulations of Climate Change-Driven Impact on Electricity Demand}

In order to evaluate the impact of future climate change on electricity consumption, we combine results from the empirical model and future predictions of climate change to simulate changes in monthly electricity demand in Tianjin by end-of-century. The study predicts end-of-century climate under the three climate scenarios (RCP2.6, RCP4.5 and RCP8.5) with 2000-2018 as the benchmark by adding the downscale changes to the historical baseline of daily temperature variation [59]. Specifically, the paper used a set of climate projections from the IPCC's Representative Carbon Pathway (RCPs) scenarios and downscaled the climate projections using a statistical downscaling technique, which is applied on the assumption that the climate is in smooth and steady change rate. We then add the downscaled climate change projections to the historical daily temperature observed by the local weather stations. This method can yield a simulated time series of daily temperature data adjusted for changes in the RCP scenarios and retaining representative daily variance in historical daily temperatures. The projected daily temperatures are then used to calculate the monthly HDD and CDD, which are used as input in the estimated empirical model for the investigation of future changes in electricity consumption. For visual display, we aggregate the monthly results to a whole year, and the simulated results of electricity demand in Tianjin under three climate scenarios are listed in Table 5. It needs to caution that the results are meant to demonstrate the changes in electricity demand driven by climate change in a business-as-usual setting, which has been used in many modeling contexts [3]. Importantly, economic growth, technology, adaptation, and current infrastructure are held constant, when we estimate the reduced-form model.

The results indicate that electricity demand in Tianjin would increase under the three climate scenarios, which reflects the substantial impact of climate change on electricity demand. The top third of Table 5 shows the summary of results under the lower-emissions scenario, RCP2.6. Comparing with 2018, the growth of electricity demand in 2099 caused by climate change under RCP2.6 scenario would be 1017 million $\mathrm{kWh}$, representing $1.2 \%$ of the total electricity consumption in Tianjin in 2018. The middle third of Table 5 simulates results for the modest warming RCP4.5 scenario. The growth of electricity demand in 2099 caused by climate change under RCP4.5 scenario would be 2210 million $\mathrm{kWh}$, representing $2.6 \%$ of the total electricity consumption in Tianjin in 2018. The bottom third of Table 5 summarizes the results under the higher-emissions scenario, RCP8.5. The growth of electricity demand in 2099 caused by climate change under RCP8.5 scenario would be 7935 million $\mathrm{kWh}$, representing $9.2 \%$ of the total electricity consumption in Tianjin in 2018. The apparent differences in electricity demand under the three climate change scenarios indicate that the regional electricity system may be strongly vulnerable to climate change when lacking climate policy intervention. Of particular note are that the impacts of CDD on Tianjin's electricity demand are much greater than HDD under the three climate scenarios. And if climate change continues, the cost for regional electricity systems to adapt to climate change would be further increased.

Next, we explore the impact of climate change on monthly electricity demand distribution in Tianjin by end of century. To capture this impact, Fig. 7 plots the predicted monthly electricity demand under RCP2.6, RCP4.5 and RCP8.5 scenarios obtained by combining the empirical model with the ensemble of climate predictions. In Fig. 7, we plotted the distribution of monthly electricity demand in 2018 (in blue) and the distribution of monthly electricity demand in 2099 under RCP2.6 (in red), RCP4.5 (in green) and RCP8.5 (in purple) scenarios without economic growth and technological progress. The height of the lines at each month represents the electricity demand (in 100 million $\mathrm{kWh}$ ). In all scenarios, except for the RCP8.5 scenario, the monthly electricity consumption in Tianjin shows a downward trend from January to April, an upward trend from April to July, a downward trend from July to October, and an upward trend from October to December, with a peak in July. As for RCP8.5 scenario, by end of century, the monthly electricity consumption in Tianjin shows a downward trend from January to February, an upward trend from February to July, a downward trend from July to November, and an upward trend from November to December, with an extremely high peak in July.

The difference in the shape of the four distribution lines shows particular implications of climate change. It is expected, even absent economic growth, that climate change would increase July's electricity consumption by 1481, 655, and 342 million $\mathrm{kWh}$ under RCP8.5, RCP4.5 and RCP2.6 scenarios respectively, by the year 2099. The above-mentioned increased electricity demands represent about $16.1 \%, 7.3 \%$ and $4.0 \%$ of 2018 July consumption. In the benchmark scenario, the electricity consumption in the months with more heating load demand are always higher than the three simulation scenarios, and in the months with more cooling load demand are always lower than the three simulation scenarios. And the RCP8.5 scenario's monthly electricity consumption is much higher than RCP2.6 and RCP4.5 scenarios in the months needing cooling load demand. Affected by climate change, the monthly peak electricity consumption in winter is becoming more and more inapparent, but the monthly peak electricity consumption in summer is becoming 


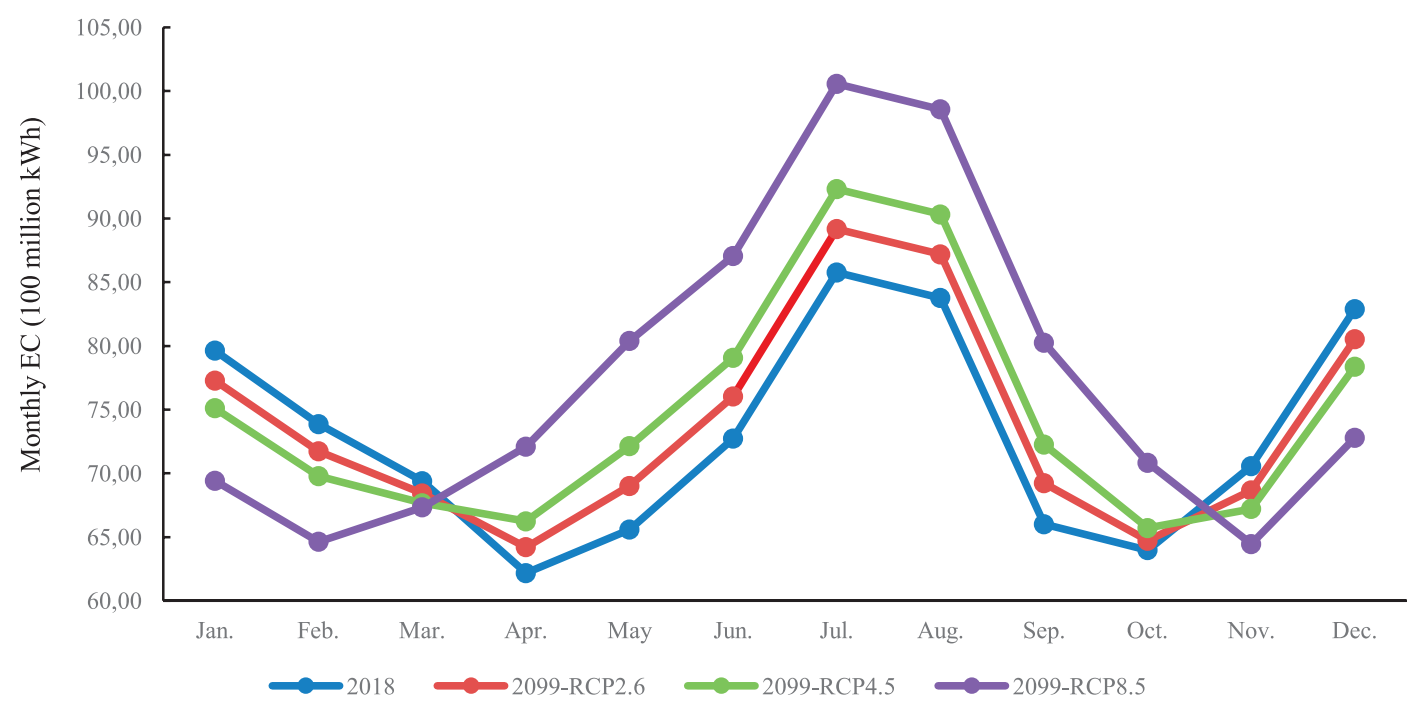

Fig. 7. Monthly electricity demand distribution in Tianjin under RCP2.6, RCP4.5, and RCP8.5 scenarios.

more and more prominent. It is also worth mentioning that, unlike other scenarios, the month with the lowest electricity demand is November in the RCP8.5 scenario and electricity consumption in July was $56 \%$ higher than that in November. The findings support the early prediction that climate change may further aggravate the peak electricity demand in hot months.

Our simulations only refer to the impact of climate change on electricity consumption and the impacts of technological progress and macroeconomic factors are not considered. Overall, if the region experiences the warmer climate that scientists predict for the future, our study shows that much greater generation capacity would be needed in Tianjin. As such, even absent economic growth, climate change may drive significant changes to the electricity supply chain.

\section{Conclusions}

In this paper, a methodological framework has been proposed to investigate the impacts of climate change on the region's monthly electricity consumption. We applied our proposed models to Tianjin and predicted end-of-century changes in monthly electricity demand of Tianjin by combining the empirical results with an ensemble of climate predictions under three Representative Concentration Pathways (RCPs). This study is essential for governments and public utilities to assess the vulnerability of the electricity sector to climate change and to formulate long-term adaptation plans and policies. The paper is concluded by summarizing the findings and corresponding implications, and discussing potential adaption options to climate change.

The panel data regression analysis revealed that the monthly electricity consumption in Tianjin is significantly influenced by climatic factors. The empirical results show that the elasticity coefficients of
HDD and CDD are 0.065 and 0.094 respectively, which could suggest that both HDD and CDD significantly influence the monthly electricity consumption in Tianjin. Interestingly, the elasticity coefficient of CDD is higher than HDD, which indicates that the cooling demand behaviors may have a greater influence on electricity consumption than heating demand behaviors. Hence, if climate change continues, the cost for electricity systems to adapt to climate change may be further increased.

The simulation results showed that climate change would increase electricity consumption by 1017, 2210 and 7935 million $\mathrm{kWh}$ under RCP2.6, RCP4.5 and RCP8.5 scenarios respectively, by the year 2099. The apparent differences in electricity demand under the three scenarios indicate that the regional electricity system is extremely vulnerable to climate change when lacking climate policy intervention. The RCP8.5 scenario monthly electricity demand is much higher than RCP2.6 and RCP4.5 scenarios in the months with cooling load demand. The different distribution of monthly electricity demand in Tianjin under RCP2.6, RCP4.5 and RCP8.5 scenarios shows particular implications of climate change. Affected by climate change, the monthly peak electricity consumption in winter may be more and more inapparent, but the monthly peak electricity demand in summer is becoming more and more prominent. Specifically, electricity consumption in July is $56 \%$ higher than that in November by end-of-century, under RCP8.5 scenario, which means that climate change may further aggravate the disparity between monthly electricity consumption.

Climate change may drive substantial changes to the electricity supply chain, and our study is indicative of a need for adaptive strategies. Development in air conditioning technologies could mitigate the aggravating disparity of monthly electricity consumption. Although continuing climate change may incentive greater 
adoption of air conditioners, it may also drive the development of more energy-efficient air conditioning technologies. Advances in air conditioning technologies would smooth the monthly electricity consumption distributions displayed in Fig. 7. Especially, both average demand and peaks would diminish when air conditioning technology is more efficient, which should be the focus of future research and financing.

The increasing penetration of renewable technologies is also a potential adaptation strategy for climate change. Increases in renewable generation could supply for some of peak demand caused by climate change and its abatement emissions could also further mitigate climate change. Facing the problem of short-term overload caused by climate changes, the implementation of renewable distributed microgrid may be the most cost-effective way to meet the temporary high electricity demand related to heat waves. Additionally, Tianjin is rich in solar and wind resources, and the renewable energy microgrid in Tianjin has great development potential.

Finally, it is essential to support electricity enterprises to upgrade the capacity of generation units and power networks in time to maintain a secure electricity system under any future climate change. Various forms of demand-side management, such as the adoption of time-varying prices, are also necessary to reduce or transfer the peak load.

In conclusion, several changes to the electricity supply chain could be reasonably envisioned to mitigate the impacts caused by climate change. But we do not intend for these suggestions to be exhaustive nor strongly advocate any particular option, the study is intended to advance the discourse of this significant and complex topic in a relatively clear and structured manner.

\section{Acknowledgements}

The authors sincerely acknowledge the financial support from the Chinese National Funding of Social Sciences (No. 2014B-0130) and the National Natural Science Foundation of China (No. 71373173).

\section{Conflict of Interest}

The authors declare no conflict of interest in this paper.

\section{References}

1. EMODI N.V., CHAIECHI T. The impact of climate change on electricity demand in Australia. Energy \& Environment, 29 (7), 1263, 2018.

2. ZHANG C., LIAO H., MI Z. Climate impacts: temperature and electricity consumption. Natural Hazards, 99 (3), 1259, 2019.
3. AUFFHAMMER M., BAYLIS P., HAUSMAN C.H. Climate change is projected to have severe impacts on the frequency and intensity of peak electricity demand across the United States. Proceedings of the National Academy of Sciences, 114 (8), 1886, 2017.

4. Rose S.K., Diaz D.B., Blanford G.J. Understanding the social cost of carbon: a model diagnostic and intercomparison study. Climate Change Economics, 8 (2), 1, 2017.

5. ALBERINI A., PRETTICO G., SHEN C., TORRITI J. Hot weather and residential hourly electricity demand in Italy. Energy, 177, 44, 2019.

6. CIALANI C., MORTAZAVI R. Household and industrial electricity demand in Europe. Energy Policy, 122 (July), 592, 2018.

7. THORNTON H.E., SCAIFE A.A., BRIAN J. The role of temperature in the variability and extremes of electricity and gas demand in Great Britain. Environmental Research Letters, 11 (11), 1, 2016.

8. DESCHÊNES O., GREENSTONE M. Climate Change, Mortality, and Adaptation: Evidence from Annual Fluctuations in Weather in the US. American Economic Journal: Applied Economics, 3 (October), 152, 2011.

9. SABBIR M., SHOURAV A., SHAHID S., SINGH B. Potential Impact of Climate Change on Residential Energy Consumption in Dhaka City. Environmental Modeling \& Assessment, 23 (2), 131, 2018.

10. NASA (National Aeronautics and Administration). Graphic: The relentless rise of carbon dioxide. Washington, DC, USA. Retrieved from https://climate. nasa.gov/climate_resources/24/graphic-the-relentless-riseof-carbon-dioxide/ 2017.

11. IPCC. Climate Change 2014 Synthesis Report Summary Chapter for Policymakers. Ipcc, 2014.

12. DARCH G. Climate change: the need to adapt sustainably. Proceedings of the Institution of Civil Engineers, 170 (November), 147, 2017.

13. Grossman M.R. Climate Change and the Individual. American Journal of Comparative Law, 66 (June), 345, 2018.

14. ZHANG Y., ZHANG K. The linkage of $\mathrm{CO}_{2}$ emissions for China, EU, and USA: evidence from the regional and sectoral analyses. Environmental Science \& Pollution Research, 20179, 2018.

15. LU C., LI W. Science of the Total Environment A comprehensive city-level GHGs inventory accounting quantitative estimation with an empirical case of Baoding. Science of the Total Environment, 651 (689), 601, 2019.

16. LI G., CAI L., CHEN L., CHEN T., ZHANG X., PAN Y. Relations of Total Electricity Consumption to Climate Change in Nanjing. Energy Procedia, 152, 756, 2018.

17. CUI H., LIU X., ZHAO Q. Which Factors Can Stimulate China's Green Transformation Process? From Provincial Aspect. Polish Journal of Environmental Studies, 30 (1), 47, 2021.

18. DECOTIS P.A. Electric-Sector Capabilities Needed to Address Climate Change. Natural Gas \& Electricity, 36 (5), 24, 2019.

19. NNAEMEKA E., TAHA C., RABIUL A.B.M. The impact of climate change on electricity demand in Australia. Energy \& Environment, 29 (7), 1263, 2018.

20. VÉLIZ K.D., KAUFMANN R.K., CLEVELAND C.J., STONER A.M.K. The e ff ect of climate change on electricity expenditures in Massachusetts. Energy Policy, 106 (March), 1, 2017. 
21. JIN J., ZHOU P., LI C., GUO X., ZHANG M. Low-carbon power dispatch with wind power based on carbon trading mechanism. Energy, 170, 250, 2019.

22. ALVI S., MAHMOOD Z., NAEEM S.M. Dilemma of direct rebound effect and climate change on residential electricity consumption in Pakistan. Energy Reports, 4, 323, 2018.

23. KLIMENKO V.V, KLIMENKO A.V, TERESHIN A.G., FEDOTOVA E.V. Impact of Climate Change on Energy Production, Distribution, and Consumption in Russia. Thermal Engineering, 65 (5), 247, 2018.

24. Gupta E. Global warming and electricity demand in the rapidly growing city of Delhi: A semi-parametric variable coefficient approach. Energy Economics, 34 (5), 1407, 2012.

25. KAUFMANN R.K., GOPAL S., TANG X., RACITI S.M., LYONS P.E., GERON N., CRAIG F. Revisiting the weather effect on energy consumption: Implications for the impact of climate change. Energy Policy, 62, 1377, 2013.

26. ZACHARIADIS T., HADJINICOLAOU P. The effect of climate change on electricity needs e A case study from Mediterranean Europe. Energy, 76, 899, 2014.

27. HOLLANDA L., TROTTER I.M., FOLSLAND T. Climate change and electricity demand in Brazil: A stochastic approach. Energy, 102, 596, 2016.

28. FAN J., HU J., ZHANG X. Impacts of climate change on electricity demand in China: An empirical estimation based on panel data. Energy, 170, 880, 2019.

29. BURILLO D., CHESTER M.V, PINCETL S., FOURNIER E.D., REYNA J. Forecasting peak electricity demand for Los Angeles considering higher air temperatures due to climate change. Applied Energy, 236 (November 2018), 1, 2019.

30. ABDEL M., ABDRABO K.A., HASSAAN M.A., ABDELRAOUF $\mathrm{H}$. Impacts of Climate Change on Seasonal Residential Electricity Consumption by 2050 and Potential Adaptation Options in Alexandria Egypt. American Journal of Climate Change, 4, 575, 2018.

31. LI X. Linking residential electricity consumption and outdoor climate in a tropical city. Energy, 157 (15), 734, 2018.

32. LI J., YANG L., LONG H. Climatic impacts on energy consumption: Intensive and extensive margins. Energy Economics, 71, 332, 2018.

33. FAZELI R., RUTH M., DAVIDSDOTTIR B. Urban Climate Temperature response functions for residential energy demand - A review of models. URBAN CLIMATE, 15, 45, 2016.

34. FIKRU M.G., GAUTIER L. The impact of weather variation on energy consumption in residential houses. Applied Energy, 144, 19, 2015.

35. WU Y., LIU H., NI Y., ZHOU J. Residents' Thermal Discomfort and Adaptive Responses of Indoor Environment in Hot Summer and Cold Winter Zone , China. Proceedings of the $7^{\text {th }}$ International Conference of SuDBE, 1, 2015.

36. HEKKENBERG M.Ã., BENDERS R.M.J., MOLL H.C., UITERKAMP A.J.M.S. Indications for a changing electricity demand pattern: The temperature dependence of electricity demand in the Netherlands. Energy Policy, 37 (4), 1542, 2009

37. BIGERNA S. Estimating temperature effects on the Italian electricity market. Energy Policy, 118 (October 2017), 257, 2018.

38. AHMED T., VU D.H., MUTTAQI K.M., AGALGAONKAR A.P. Load forecasting under changing climatic conditions for the city of Sydney, Australia. Energy, 142, 911, 2018.

39. MOHAMMED N.A. Modelling of unsuppressed electrical demand forecasting in Iraq for long term. Energy, 162, 354, 2018

40. CHANG Y., SIK C., MILLER J.I., PARK J.Y., PARK S. A new approach to modeling the effects of temperature fluctuations on monthly electricity demand. Energy Economics, 60, 206, 2016

41. WANG S., SUN X., LALL U. A hierarchical Bayesian regression model for predicting summer residential electricity demand across the U.S.A. Energy, 140, 601, 2017.

42. LOHSE R., RIEL M. The Economic Challenges of Deep Energy Renovation - Differences, Similarities, and Possible Solutions in Central Europe: Austria and Germany. ASHRAE TRANSACTIONS, 122, 69, 2016.

43. DAMETTE O., MARQUES A.C. Renewable energy drivers: a panel cointegration approach. Applied Economics, 00 (00), 1, 2018.

44. KIPPING A., TRØMBORG E. Hourly electricity consumption in Norwegian households e Assessing the impacts of different heating systems. Energy, 93, 655, 2015.

45. MANN H.B. Nonparametric Tests Against Trend. Econometrica, 13 (3), 245, 1945.

46. KENDALL M.G. Rank Correlation Methods, C. Grifin, Ed.) (4th Editio.). London, 1975.

47. GOCIC M., TRAJKOVIC S. Analysis of changes in meteorological variables using Mann-Kendall and Sen's slope estimator statistical tests in Serbia. Global and Planetary Change, 100, 172, 2013.

48. OKUI R., YANAGI T. Panel data analysis with heterogeneous dynamics. Journal of Econometrics, 222 (2), 451, 2019.

49. LEVIN A., LIN C., CHU C.J. Unit root tests in panel data: asymptotic and finite-sample properties. Journal of Econometrics, 108 (1), 1, 2002.

50. BILAL A., SHERWANI R.A.K. Multilevel Growth Modeling using R: A Case of GDP influencing Factors. Journal of Statistics, 24 (1), 1, 2017.

51. OLANREWAJU B.T., OLUBUSOYE O.E., ADENIKINJU A., AKINTANDE O.J. A panel data analysis of renewable energy consumption in Africa. Renewable Energy, 140, 668, 2019.

52. LU X., SU L. Determining individual or time effects in panel data models. Journal of Econometrics, 2019.

53. RIAHI K., RAO S., KREY V., CHO C., CHIRKOV V., FISCHER G. RCP 8.5 - A scenario of comparatively high greenhouse gas emissions. Climatic Change, 109, 33, 2011.

54. IPCC. Climate change 2013: The fifth assessment report Cambridge university press Cambridge, 2013.

55. CHEN S., LI Z., LIU F., YANG S., LI M. Risk evaluation of solar greenhouse cucumbers low temperature disaster based on GIS spatial analysis in Tianjin, China. Geomatics, Natural Hazards and Risk, 10 (1), 576, 2019.

56. XinHuaNet. Tianjin Power Grid's maximum load has reached a record high for two days in succession. Retrieved from http://www.xinhuanet.com/politics/201907/27/c 1124806624.htm n.d.

57. RUTH ${ }^{-}$M., LIN A. Regional energy demand and adaptations to climate change: Methodology and application to the state of Maryland , USA. Energy Policy, 34, 2820, 2006 
58. LI M., CAO J., GUO J., NIU J., XIONG M. Response of energy consumption for building heating to climatic change and variability in Tianjin City, China. Meteorological Applications, 131 (November 2015), 123, 2016.

59. AUFFHAMMER M., HSIANG S.M. Using Weather Data and Climate Model Output in Economic Analyses of Climate Change. Review of Environmental Economics and Policy, 7 (2), 181, 2013)
60. SUN Q., MIAO C., DUAN Q. Projected changes in temperature and precipitation in ten river basins over China in $21^{\text {st }}$ century. International Journal of Climatology, 35 (5), 1125, 2015.

61. TAO Y., YANG T. Non-stationary bias correction of monthly CMIP5 temperature projections over China using a residual-based. International Journal of Climatology, $\mathbf{3 8}$ (1), 467, 2017. 